\title{
Comparative Study on the Extraction of Bioactive Compound from Banana and Pineapple Peel Extract
}

\author{
Nurdalilah Othman ${ }^{1}$, Yi Peng Teoh ${ }^{1}$, Zhong Xian Ooi ${ }^{3}$ and Sung Ting Sam ${ }^{4}$ \\ ${ }^{1}$ Department of Chemical Engineering Technology, Faculty of Engineering Technology, Universiti Malaysia \\ Perlis (UniMAP), P.O Box 77, D/A Pejabat Pos Besar, 01000 Kangar, Perlis, Malaysia. \\ (e-mail: nurdalilahothman@gmail.com). \\ ${ }^{2}$ Department of Chemical Science, Faculty of Science, Universiti Tunku Abdul Rahman, Jalan Universiti, \\ Bandar Barat, 31900 Kampar, Perak, Malaysia. (e-mail: zhongxian.ooi@gmail.com). \\ School of Bioprocess Engineering, Universiti Malaysia Perlis (UniMAP), Kompleks Pusat Pengajian Jejawi 3, \\ 02600 Arau, Perlis, Malaysia. (e-mail: stsam@unimap.edu.my).
}

\begin{abstract}
In this study, comparative phytochemical analysis of total phenolics content (TPC), total flavonoids content (TFC), total tannins content (TTC) and in vitro analysis of antioxidant assay for DPPH radical scavenging activity and ferric iron reducing assay (FRAP) of two different extracts, from the fruit peels of banana $(B P)$ and pineapple (PIP) were determined using spectrophotometric methods. TPC, TFC, TTC, DPPH antioxidant assay and FRAP assay from methanolic BP extract was higher compared to PIP with the values $2.9330 \mathrm{mg} \mathrm{GAE} / \mathrm{g}$ of extract, $1.2175 \mathrm{mg} Q A E / \mathrm{g}$ of extract and $0.1520 \mathrm{mg}$ GAE/g of extract respectively. The antioxidant assay showed higher in BP extract compared to PIP extract with the scavenging activity of $32.18 \%$ and increment of reducing power ability when the concentration increased. BP was chosen to conduct a biosynthesis of nanoparticles which can be applied in many fields.
\end{abstract}

Keywords: Fruit peels, phytochemical analysis, in vitro analysis, nanoparticles.

\section{Introduction}

Global fruit production has experienced an outstanding increase. Over the last decade, about 3 percent output has been growing annually. In 2011, almost 640 million tonnes of fruits were gathered throughout the world and India become the second largest fruit producer after China. According to the Department of Statistics Malaysia, banana and pineapple fruits are the examples of fruit agricultural that contribute to the increment in import dependency ratio from year 2013 to 2014 [1]. In Malaysia, pineapple uses $6.3 \%$ agrofood area which fourth largest area after durian (41.3\%), banana (18.0\%) and rambutan (9.8\%) [2].

Non-edible plant produced are believed to be rich in bioactive secondary metabolites and they are cheap renewable feedstocks [3]. Based on evidence on the higher level as protective agents against cardiovascular diseases and some cancers, WHO recommended a minimum daily intake of $400 \mathrm{~g}$ of fruit and vegetables must be observed thus led to '5-a-day' fruit and vegetable campaign launched in many countries [4]. On the other hand, majority of the fruits produced are processed to extend their availability all over the year as they are seasonal and have low shelf-life. So, fruits are usually processed into juices, bottle fruits, bars, jams, jellies, marmalades, pickles and dried fruits. However, fruit processing produces a great quantity of wastes.

By-products or fruit wastes from fruits processing industry mainly in the form of seed, pomace, pulp and peel which contain a large amount of water caused them to be wet and easily fermentable. If there is no further processed, these agrowastes produced odor, soil pollution, harborage for insects and give impact to serious environmental pollution [5]. In past research, some efforts have been done by utilized agrowastes essentially for 
livestock feed and fuel purposes. Recently, scientists were able to develop high value added products from agrowastes such as cosmetics, medicine and water treatment which seems to be economically attractive [6].

The new idea in utilizing fruit by-products mainly fruit peels which in some fruit signify almost $30 \%$ of the total weight become a great attention especially when researchers found that peels possessed better biological activities compared to other parts of fruits. More recently, with the gaining interest for natural sources of bioactive secondary metabolites, food products and high added products enriched in fruit peels have been developed. However, the potential of fruits peels in products highly depended on their chemical composition. Hence in this study, the comparative study had been investigated on the banana (Musa paradisiaca) and pineapple peels (Ananas comusus) with the aim of exploiting the potential value of these peels.

\section{Procedure for Paper Submission}

\subsection{Materials}

Agricultural residues such as pineapple peels (PIP) and banana peels (BP) were obtained from a local food stall at Kangar, Perlis, Malaysia.

\subsection{Chemicals}

All tables and figures you insert in your document are only to help you gauge the size of your paper, for the convenience of the referees, and to make it easy for you to distribute preprints.

\subsection{Sample Pretreatment}

Agricultural residues collected and washed with distilled water and dried in oven for 24 hours at $60^{\circ} \mathrm{C}$. The sample then were ground to $125 \mu \mathrm{m}$ were collected and defatted using $n$-hexane (ratio of solid/liquid 1/10, w/w) at room temperature and then the solvent was evaporated.

\subsection{Preparation of Peel's Extracts}

The extraction of phenolic compounds was carried out using solvents $80 \%$ methanol. The powdered samples were added to a solvent 1:10 mixed well and kept at room temperature, for 3 days under constant stirring. The mixture was centrifuged at 6,000 rpm for $15 \mathrm{~min}$ and the supernatant was filtered through a filter paper. Then, the solvent was evaporated in a rotavapor. The extraction yield was expressed as dry matter percentage.

\subsection{Total Phenolics Content (TPC)}

Total polyphenols analysis was performed by the colorimetric method with some modifications. The sample was re-dissolved in the extraction medium. Methanolic solution of $1 \mathrm{mg} / \mathrm{ml}$ was used in the analysis. The reaction mixture was prepared by missing $0.5 \mathrm{ml}$ of methanolic extract solution, $2.5 \mathrm{ml}$ of $10 \%$ Folin-Ciocalteu reactive dissolved in water and $2.5 \mathrm{ml}$ of $7.5 \%$ aqueous solution of $\mathrm{Na}_{2} \mathrm{CO}_{3}$. The mixture was kept for $30 \mathrm{~min}$ in the dark at room temperature. The absorbance was read at $765 \mathrm{~nm}$ using a UV/Vis spectrophotometer (UV Mini1240; Shimadzu, Japan). Gallic acid $(10-50 \mu \mathrm{g} / \mathrm{ml})$ was used for constructing the standard curve, and the results were expressed as $\mathrm{mg}$ of gallic acid equivalents (GAE)/ $\mathrm{g}$ of extract. The samples were triplicates.

\subsection{Total Flavonoids Content (TFC)}

Total flavonoid content was determined by a colorimetric method. $0.5 \mathrm{ml}$ extracts were added to $2 \mathrm{ml}$ distilled water and mixed with $5 \%$ of $0.15 \mathrm{ml} \mathrm{NaNO}$. After reacting for $5 \mathrm{~min}, 0.15 \mathrm{ml} 10 \% \mathrm{AlCl}_{3} \cdot 6 \mathrm{H}_{2} \mathrm{O}$ solution was added. After another 5 minutes, $1 \mathrm{ml} 1 \mathrm{M} \mathrm{NaOH}$ was added. The reaction solution was well mixed and kept for $15 \mathrm{~min}$. The absorbance was determined at $415 \mathrm{~nm}$ using a UV/Vis Spectrophotometer (UV Mini1240; Shimadzu, Japan). Quercetin $(5-100 \mu \mathrm{g} / \mathrm{ml})$ was used for constructing the standard curve, and the results were expressed as $\mathrm{mg}$ og quercetin equivalents (QAE)/g of extract. The samples were triplicates. 


\subsection{Total Tannins Content (TTC)}

The tannins were determined by calorimetric method. About $0.1 \mathrm{ml}$ of the sample extract was added to a volumetric flask containing $7.5 \mathrm{ml}$ of distilled water, $0.5 \mathrm{ml}$ of Folin Ciocalteu reactive, $1 \mathrm{ml}$ of $35 \% \mathrm{Na}_{2} \mathrm{CO}_{3}$ solution. The mixture solution then was diluted to $10 \mathrm{ml}$ with distilled water. The mixture was shaken well and kept at room temperature for $30 \mathrm{~min}$. The absorbance was read at $725 \mathrm{~nm}$ using a UV/Vis spectrophotometer (UV Mini-1240; Shimadzu, Japan). Gallic acid $(2-100 \mu \mathrm{g} / \mathrm{ml})$ was used for constructing the standard curve, and the results were expressed as $\mathrm{mg}$ of gallic acid equivalents (GAE)/ $\mathrm{g}$ of extract. The samples were triplicates.

\subsection{DPPH (1,1-diphenyl-2-picrylhydrazyl) Radical Scavenging Assay}

The electron donation ability of the obtained methanol extracts of agricultural residues was measured by bleaching of the purple coloured solution of DDPH (1,1-diphenyl-2-picrylhydrazyl) radical according to the method. Methanolic extracts $(0.5 \mathrm{ml})$ were added to $5 \mathrm{ml}$ of $0.06 \mathrm{mM}$ DDPH. After incubation period of $30 \mathrm{~min}$ at room temperature, the absorbance was measured against a blank at $515 \mathrm{~nm}$ using UV/Vis spectrophotometer (UV Mini-1240; Shimadzu, Japan) versus methanol as a blank. The \% inhibition was calculated by the following equation: (Abs blank $\left.-\mathrm{Abs}_{\text {sample }} / \mathrm{Abs}_{\text {blank }}\right) \times 100$, where blank is the absorption of the DPPH solution and sample is the absorption of the DPPH solution after the addition of the sample. The antioxidant assay was expressed as percentage and the samples were triplicates.

\subsection{Ferric Reducing Ability Power (FRAP) Assay}

The reducing antioxidant power of peel methanolic extract was determined using calorimetric method. 2.5 $\mathrm{ml}$ of methanolic extract at different concentration $(31.25-1000 \mu \mathrm{g} / \mathrm{ml})$ were mixed with phosphate buffer $(2.5$ $\mathrm{ml}, \mathrm{pH}$ 6.6) and potassium ferricyanide $(2.5 \mathrm{ml}, 1 \%)$. The mixture was placed in water bath for $50^{\circ} \mathrm{C}$ for 20 minutes. Then, $2.5 \mathrm{ml}$ of $1 \%$ trichloroacetic acid was added to the mixture and the mixture centrifuged at 3000 rpm for 10 minutes. The upper layer of the solution $(2.5 \mathrm{ml})$ was then added with $2.5 \mathrm{ml}$ distilled water and 0.5 $\mathrm{ml}$ of $\mathrm{FeCl}_{3}(0.1 \%$ solution $)$ and let the reaction occur for 10 minutes. The absorbance was read at $700 \mathrm{~nm}$ using a UV/Vis spectrophotometer (UV Mini-1240; Shimadzu, Japan). Ascorbic acid (31.25 - $1000 \mu \mathrm{g} / \mathrm{ml}$ ) was used for constructing the standard curve. The samples were triplicates. Increased absorbance of the reaction mixture indicates increase in reducing power. Ascorbic acid was used as standard.

\section{Results and Discussion}

In this recent years, an increased attention has been aimed on the industrial wastes, especially those containing residual phenols from used plant raw material. PIP and BP are example of the important dietary sources of antioxidant properties [7]-[8].

Calorimetric analysis of polyphenolic, flavonoid and tannins content indicated that the methanolic extract of BP had highly amounts of TPC, TFC and TTC compared to PIP and this in agreement with [9] who studied the chemical composition of selected fruit peels. The polyphenols, flavonoids and tannins content in BP extract was $2.9330 \mathrm{mg} / \mathrm{g}$ of dry weight of extract, expressed as gallic acid equivalents, $1.2175 \mathrm{mg} / \mathrm{g}$ of dry weight of extract, expressed as quercetin equivalents and $0.1520 \mathrm{mg} / \mathrm{g}$ of dry weight of extract, expressed as gallic acid equivalents respectively. A significant lower of the TPC, TFC and TTC in PIP which the values were $1.7170 \mathrm{mg} / \mathrm{g}$ of dry weight of extract, expressed as gallic acid equivalents, $0.2675 \mathrm{mg} / \mathrm{g}$ of dry weight of extract, expressed as quercetin equivalents and $0.0164 \mathrm{mg} / \mathrm{g}$ of dry weight of extract, expressed as gallic acid equivalents respectively. The $\mathrm{r}^{2}$ for gallic acid in TPC is 0.9997 , for quercetin in TFC is 0.9996 while for gallic acid in TTC is 0.9918 . The standard curve for TPC, TFC and TTC showed in Fig 1 to Fig 3. In biosynthesizing of nanoparticles, phenolic compounds play an important role for reduction and stabilization [10]. 
Total Phenol Content (TPC)

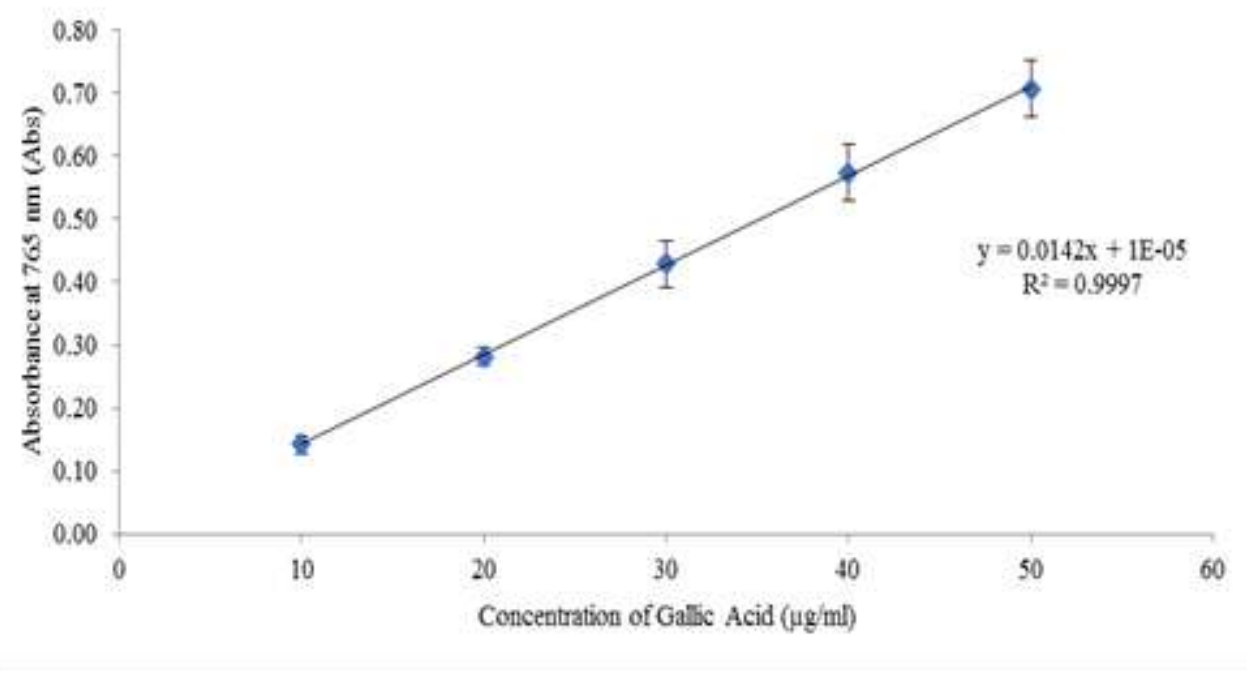

Fig. 1: Graph Absorbance at $765 \mathrm{~nm}$ (Abs) against Concentration of Gallic Acid $(\mu \mathrm{g} / \mathrm{ml})$

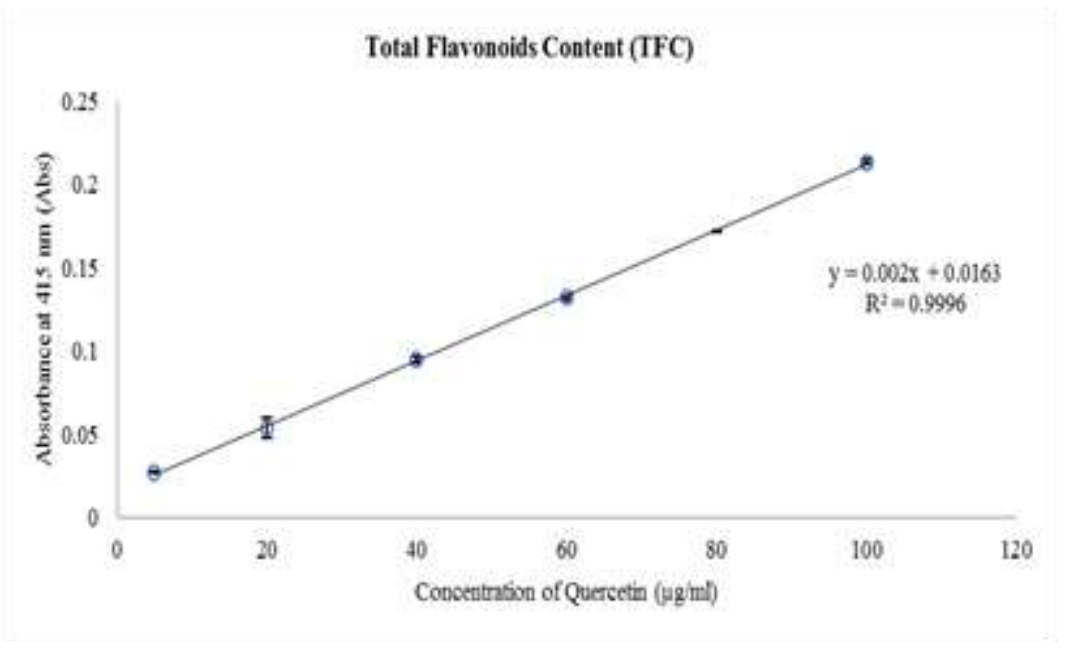

Fig. 2: Graph Absorbance at $415 \mathrm{~nm}$ (Abs) against Concentration of Quercetin ( $\mu \mathrm{g} / \mathrm{ml})$

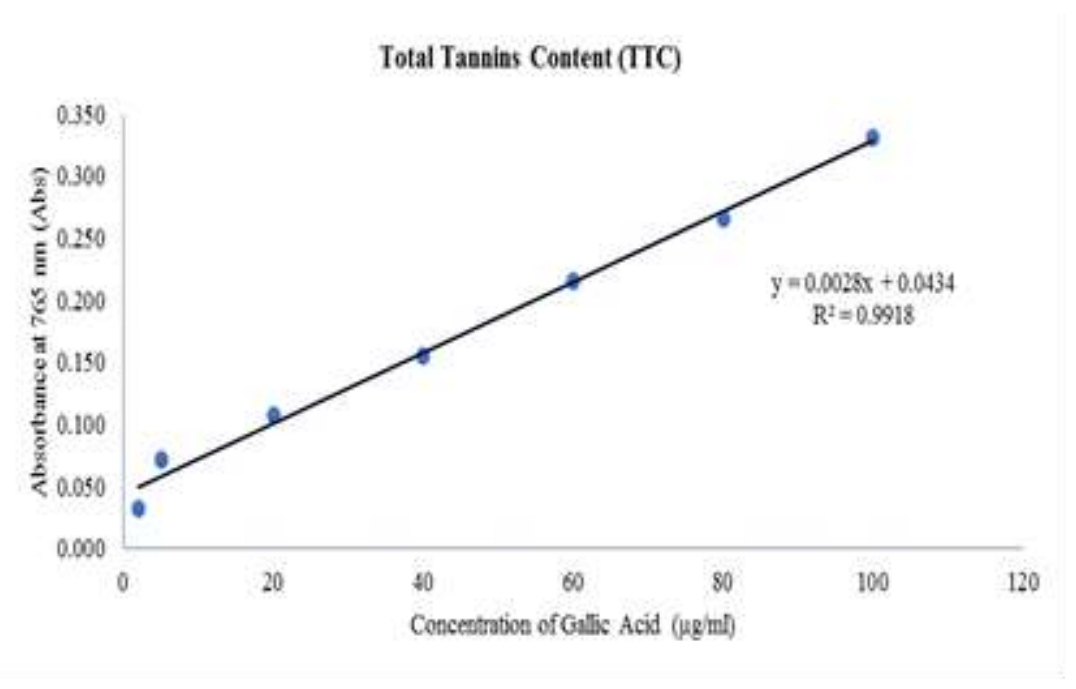

Fig. 3: Graph Absorbance at $765 \mathrm{~nm}$ (Abs) against Concentration of Gallic Acid $(\mu \mathrm{g} / \mathrm{ml})$ 
The decrease in absorbance of DPPH radical is caused by antioxidant through the reaction between antioxidant molecule and radical results in the scavenging of the radical by hydrogen donation. In this study, the BP extract was found to be higher in scavenging activity with $38.18 \%$ while in PIP was only $26.24 \%$. The significant linear correlation was confirmed between the values for the phenolic content and antioxidant activity of fruit peel extracts. The highest content of phenolic compounds indicated that these compounds contribute to the antioxidant activity [11]-[12].

TABLE I: TPC, TFC, TTC and DPPH Antioxidant Assay in Fruit Peels

\begin{tabular}{lllll}
\hline \hline Fruits & $\begin{array}{l}\text { TPC } \\
\text { (g GAE/mg of } \\
\text { extract) }\end{array}$ & $\begin{array}{l}\text { TFC } \\
\text { (g QAE/mg of } \\
\text { extract) }\end{array}$ & $\begin{array}{l}\text { TTC } \\
\text { (g GAE/mg of } \\
\text { extract) }\end{array}$ & $\begin{array}{l}\text { DPPH } \\
\text { antioxidant assay } \\
\text { (\%) }\end{array}$ \\
\hline Banana peels (BP) & 2.9330 & 1.2175 & 0.1520 & 32.18 \\
Pineapple peels (PIP) & 1.7170 & 0.2675 & 0.0164 & 26.24 \\
\hline
\end{tabular}

The BP extract showed the highest reducing power ability compared to PIP extract at various concentration. Regarding to the iron reducing power assay, it is found that there is a tight relationship between the amount of phenolic content and reducing power ability. These results were previously indicated that the reducing power ability of bioactive secondary metabolites is linked with antioxidant activity [13]-[14]. Thus, it is required to determine the reducing power ability of phenolic constituents to clarify the relationship between their antioxidant effects and the reducing power ability. However, in this studied, the ability of reducing power of the methanolic extracts for both BP and PIP were significantly lower than the synthetic antioxidant, ascorbic acid (Fig 4).

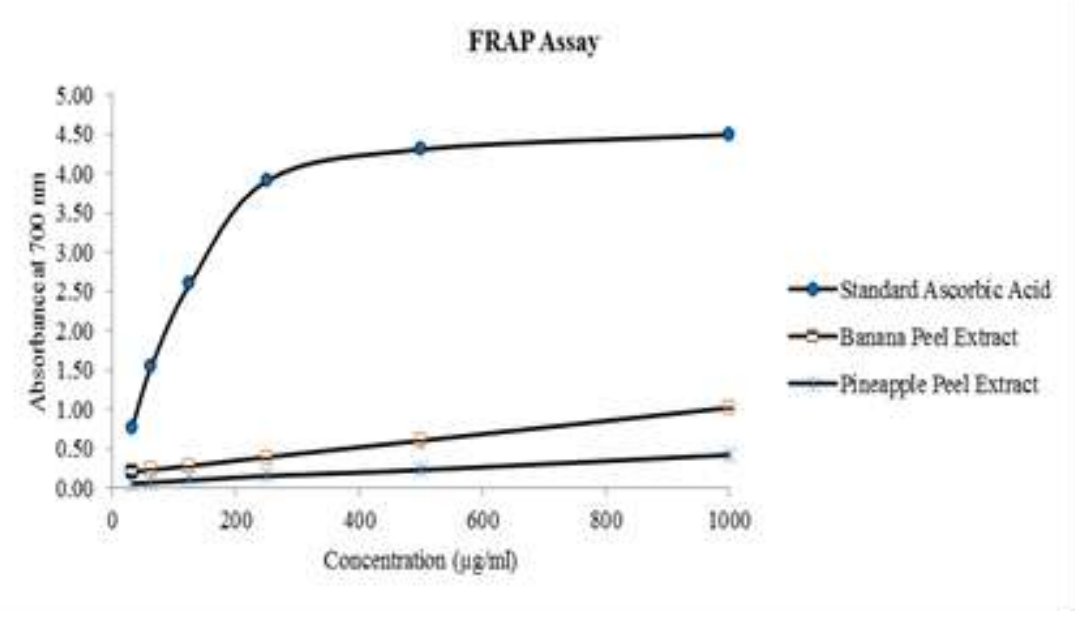

Fig. 4: Iron Reducing Power Ability of BP and PIP at various concentration

\section{Conclusion}

It could be concluded that banana peels extract has higher TPC, TFC, TTC, DPPH scavenging activity and also iron reducing power ability compared to pineapple peels extract. Instead of the phenolic content in peel itself, methanol which the highest polar solvent also played a vital role in extraction process. With the collected data for this analysis from UV-Vis spectrometer, it can be concluded that banana peel extract has potential to be conducted for further in research mainly in synthesizing of nanoparticles which this high value-added product can be applied either in food, pharmaceutical and environmental scopes.

\section{Acknowledgment}

The authors would like to acknowledge the support from the Fundamental Research Grant Scheme (FRGS) under a grant number of FRGS/1/2015/TK02/UNIMAP/02/05 (Grant Account No.: 9003-00528) from the Ministry of Higher Education. 


\section{References}

[1] H. Mei Kei, "Supply and utilization accounts selected agricultural commodities, Malaysia 2010 - 2014," Department of Statistics Malaysia, Official Portal, 2015. [Online]. Available: https://www.dosm.gov.my/v1/index.php?r=column/ctheme\&menu_id=Z0VTZGU1UHBUT1VJMFlpaXRRR0xpdz09 \&bul_id=ZzNBdUIWT214NE4xNCt6U2VNc1Q2QT09.

[2] N. Abd Halim, "Policy Intervention for the Development of the Pineapple Industry in Malaysia," Food Fertil. Technol. Cent. Asian Pacific Reg., p. 65, 2016.

[3] S. M. Omar, G. C. Azucena, and S. V. Raul, "Agricultural residues as a source of bioactive natural products," Phytochem. Rev., vol. 11, no. 4, pp. 447-466, 2012.

[4] O. Oyebode, V. Gordon-Dseagu, A. Walker, and J. S. Mindell, "Fruit and vegetable consumption and all-cause, cancer and CVD mortality: analysis of Health Survey for England data," J. Epidemiol. Community Health, vol. 68, pp. 856862, 2014.

[5] R. Shalini and D. K. Gupta, "Utilization of pomace from apple processing industries: A review," J. Food Sci. Technol., vol. 47, no. 4, pp. 365-371, 2010.

[6] I. S. Ashoush and M. G. E. Gadallah, "Utilization of Mango Peels and Seed Kernels Powders as Sources of Phytochemicals in Biscuit," World J. Dairy Food Sci., vol. 6, no. 1, pp. 35-42, 2011.

[7] U. K. Ibrahim, N. Kamarrudin, M. U. H. Suzihaque, and S. A. Hashib, "Local Fruit Wastes as a Potential Source of Natural Antioxidant: An Overview," 2016.

[8] W. Suttirak and S. Manurakchinakorn, "In vitro antioxidant properties of mangosteen peel extract," J. Food Sci. Technol., vol. 51, no. 12, pp. 3546-3558, 2014.

[9] F. D. Romelle, A. Rani, and R. S. Manohar, "Chemical composition of some selected fruit peels," Eur. J. Food Sci. Technol., vol. 4, no. 4, pp. 12-21, 2016.

[10] A. Dzimitrowicz, P. Jamróz, G. C. diCenzo, I. Sergiel, T. Kozlecki, and P. Pohl, "Preparation and characterization of gold nanoparticles prepared with aqueous extracts of Lamiaceae plants and the effect of follow-up treatment with atmospheric pressure glow microdischarge," Arab. J. Chem., 2016.

[11] G. Piluzza and S. Bullitta, "Correlations between phenolic content and antioxidant properties in twenty-four plant species of traditional ethnoveterinary use in the Mediterranean area.," Pharm. Biol., vol. 49, no. 3, pp. 240-7, 2011.

[12] M. M. Rashad, A. E. Mahmoud, M. M. Ali, M. U. Nooman, and A. S. Al-Kashef, "Antioxidant and anticancer agents produced from pineapple waste by solid state fermentation," Int. J. Toxicol. Pharmacol. Res., vol. 7, no. 6, pp. 287296, 2015.

[13] J. A. Larrauri, P. Rupérez, L. Bravo, and F. Saura-Calixto, "High dietary fibre powders from orange and lime peels: Associated polyphenols and antioxidant capacity," Food Res. Int., vol. 29, no. 8, pp. 757-762, 1996.

[14] Y. Q. Ma, J. C. Chen, D. H. Liu, and X. Q. Ye, "Effect of ultrasonic treatment on the total phenolic and antioxidant activity of extracts from citrus peel," J. Food Sci., vol. 73, no. 8, 2008. 